\title{
AFM and pulsed laser ablation methods for Cultural Heritage: application to archeometric analysis of stone artifacts
}

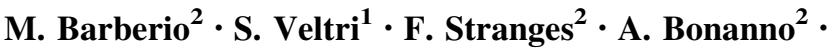 \\ F. $\mathrm{Xu}^{2} \cdot$ P. Antici ${ }^{1}$
}

Received: 26 January 2015/Accepted: 8 May 2015/Published online: 2 June 2015

(C) Springer-Verlag Berlin Heidelberg 2015

\begin{abstract}
In this paper, we introduce the use of the atomic force microscope (AFM) and of the pulsed laser ablation as methods for morphological diagnostic with nanoscale precision of archeological artifacts and corrosive patina removal from stone artifacts. We test our methodology on stone artifacts extracted from the Church of Sotterra (located in Calabria, South Italy). The AFM microscopy was compared with different petrographic, chemical, optical and morphological analysis methods for identifying the textural characteristics, evaluating the state of preservation and formulating some hypotheses about the provenance and composition of the impurity patina located on the artifact surfaces. We demonstrate that with the nanometric precision obtained with AFM microscopy, it is possible to distinguish the different states of preservation, much better than using conventional petrographic methods. The surface's roughness is evaluated from very small artifact's fragments, reducing the coring at micrometric scale with a minimal damage to the artworks. After the diagnosis, we performed restoration tests using the pulsed laser ablation (PLA) method and compared it with the more common micro-sandblasting under dry conditions. We find that the PLA is highly effective for the removal of the surficial patina, with a control of a few hundreds of nanometers in the cleaning of surface, without introducing
\end{abstract}

M. Barberio

marianna.barberio@fis.unical.it

1 EMT Research Center, Institut National de la Recherche Scientifique (INRS), 1650 Boul. Lionel-Boulet, Varennes, QC J3X 1S2, Canada

2 Biology, Ecology and Earth Science Department, University of Calabria and INFN Italy, Via Bucci 4B, 87036 Rende, CS, Italy chemical or morphological damages to the artifacts. Moreover, PLA can be easily implemented in underwater conditions; this has the great advantage that stone and pottery artifacts for marine archeological sites do not need to be removed from the site.

\section{Introduction}

Correct interpretation on the age and the history of Cultural Heritage requires the use of very sensitive diagnostic techniques, which allow identifying constituent materials and, from there, to understand the origin of the artwork. This information is required when designing a restoration project, which preserves not only the visible aspect of the artworks but also their original chemical and mineralogical composition. The diagnostic and restoration methods are, generally, based on physical and chemical methods for defining the properties of the artifacts and better conceive the restoration and conservation projects [1-5]. Unfortunately, in most cases, they give only a macroscopic description of the artifacts on a scale in the order of millimeters or microns, without being able to control the corrosive patina on the surfaces and the damage caused by the restoration processes with higher spatial precision, e.g., on a nanometric scale.

The corrosive patina on the artworks can seriously damage the artifacts and thus change their aesthetical aspect. The patina can strongly modify the chemical composition, provoking in the worst case the complete destruction of artwork, as in the cases of bronze cancers (malachite and cuprite) and in the case of biological films on ceramic and stones exposed to biological agents. In the first case, malachite and cuprite films generate red and green stains, which are often visible in many statues, and 
simultaneously destroy the bronze league. The micrometric biological films on many stone monuments cause the formation of a green skin, which completely covers the artifacts or generates holes, cavities and fractures in the artifact. This results in deterioration of the artifact. A nanometric control is, then, highly desirable since it allows removing the corrosive patina in its initial phase of formation with a strong reduction-in time and in cost-of the restoration process, thus making all conservation actions more efficient.

In this work, we propose the use of two well-known physical analysis methods, the atomic force microscopy (AFM) and the pulsed laser ablation (PLA), as support to the more common Cultural Heritage analysis methods, in order to have a nanometric control on the morphological properties of the stone artifacts and to have the controlled removal of the nanometric patina layer. These two methods are routinely applied in the field of nanoscience and nanotechnology for the growth and characterization of nanomaterials, with a control in the few to hundreds of nanometers scale. These dimensions are comparable to the initial phase of the formation of a corrosive and biological patina on the artifacts. In this paper, we demonstrate the effectiveness of these methods in a particular case study using some stone artifacts extracted from the Church of Sotterra (Paola, Calabria, Italy). We applied the AFM and PLA methods jointly with the common diagnostic methods (in situ and in laboratory), in order to characterize the materials, identify the pits of their origin, detect the chemical composition of surface patina and define a strategy for the restoration and conservation [5-10].

The Church is located in an underground site on the Tyrrhenian coast of South Italy (see the geographical collocation in Fig. 1a). Its architecture is Paleo-Christian and can be described as a basilica with a single nave, rectangular and slightly elongated, terminating in an apse, with smooth walls and divided up by three arches made of local stone (Fig. 1b) [11]. In addition, the Church is considered as one of the main representation of Byzantine art in Calabria [11, 12]. A strong moist environment, caused by frequent flooding, characterizes the Church atmosphere and contributes to the formation of a corrosive patina on the surface and in the deterioration of paints and stone artifacts. Several restoration processes, conducted since the Middle Ages, make it difficult to identify the original materials and the dating of the Church. A dating of the Church, based on the analysis of some paint pigments, indicates that in the first Middle Ages, the Church was already built, while some ecclesiastic documents indicate that the consecration and construction of Church occurred only in the late Middle Ages [11-13]. A dating process of the Church using direct methods such as thermoluminescence of radiocarbon is impossible due to the absence of any ceramic, wood or organic (tissues, bones, etc.) remains, the only artifacts attributable to the original construction being the floor, the altar and the paints. Hence, a deeper analysis is necessary to better understand the pits of provenience of the materials and to better define the origin of the Church.

Our analysis has been made based on eight stone fragments taken from the floor and the altar and using (1) optical (OM), (2) SEM and (3) AFM microscopies and (4) EDX (energy-dispersive X-ray analysis), (5) XPS (X-ray photoelectron emission), (6) XRF (X-ray fluorescence) and (7) PL (photoluminescence) spectroscopies. Moreover, each sample was restored with the pulsed laser ablation [14] to check whether this method can be considered an alternative to those conventionally used in situ [15]. For Italian Cultural Heritage, conventional restorative processes are regulated by the UNI Normal standards [16] They suggest very different restorative processes: (1) laser ablation (continuous laser) cleaning with water spray, (2) micro-sandblasting under dry condition, (3) cleanup by chemical solvents (distilled water, solvents and slightly basic solutions such as AB57, the ICR and ammonium carbonate) and (4) technical extraction of soluble salts by chemical reactions. The choice of the correct methods to be applied depends on the artifact's materials and on their conservation status.

\section{Materials and methods}

The experiments were conducted on a series of samples (C1-C8) with dimensions of $1 \mathrm{~cm} \times 1 \mathrm{~cm}$ sand and a thickness of about $2 \mathrm{~cm}$ (Fig. 1c). All samples are composed, in a first analysis, of stone and are strongly deteriorated by moist and biological agents, as witnessed by the presence of a white patina on the surface. The samples were taken from different sites distributed on the floor and on the altar of the Church, as indicated in Fig. 1c. Each sample was subject to petrographic, chemical, optical and morphological analyses using the main techniques employed in the field of Cultural Heritage (X-ray photoelectron spectroscopy-XPS, X-ray fluorescence spectroscopy-XRF, energy-dispersive X-ray-EDX, photoluminescence-PL, scanning electron microscope-SEM, atomic force microscope-AFM), in order to identify the mineralogical and chemical composition of the materials and their alterations. Moreover, after the characterization of the samples, their surface was treated by a pulsed laser ablation (LA) cleaning process in order to eliminate the surface patina [17]. This process was compared with the traditional method of microsandblasting conducted under dry condition [15]. All the chemical, optical and morphological analyses have been conducted before and after the cleaning process.

The mineralogical and petrographic studies of the collected samples were performed by optical microscopy $(\mathrm{OM})$ 

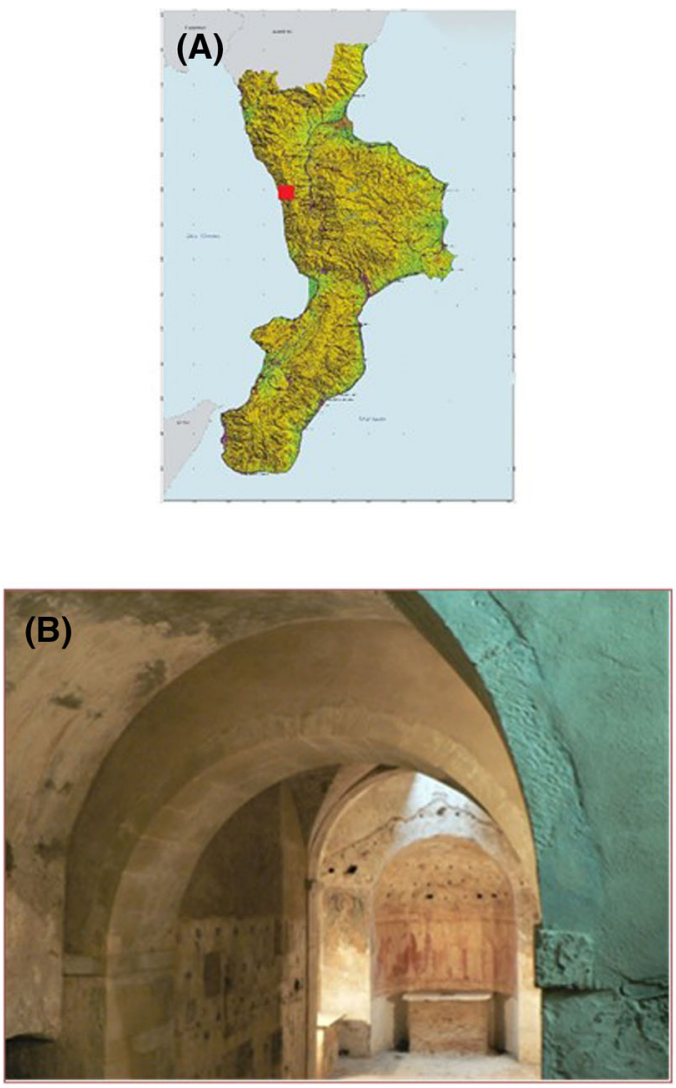

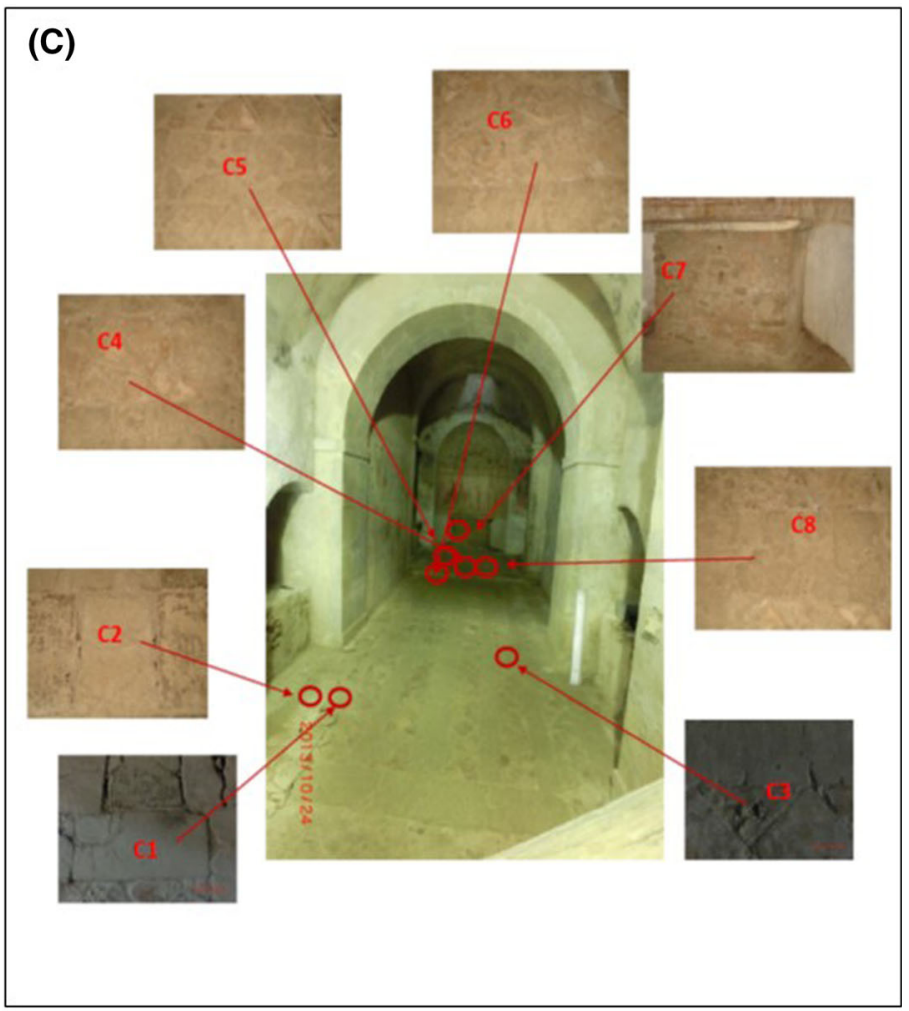

Fig. 1 Archeological site: a geographical position, b the inside of the Church, $\mathbf{c}$ samples and position where they have been found within the Church

on thin sections using a Zeiss-Axioplane microscope equipped with polarizing and reflected optical light. Chemical analysis was performed by XPS and XRF spectroscopies to obtain information on both surfaces (XPS) and the bulk (XRF) of the artifacts. XPS measurements were conducted in an ultra-high vacuum (UHV) chamber equipped for standard surface analysis with a pressure in the range of $10^{-9}$ Torr. Non-monochromatic $\mathrm{Mg}-\mathrm{K} \alpha \mathrm{X}$-ray ( $h v=1253.64 \mathrm{eV}$ ) was used as excitation source. The XPS spectra were calibrated with the $\mathrm{C} 1 \mathrm{~s}$ peak of a pure carbon sample (energy position $284.6 \mathrm{eV}$ ), and the data were fitted, assuming a Gaussian distribution. XRF measurements were conducted with a X-123 SDD apparatus (Amptek, USA), equipped by a gold cathode and a beryllium revelator, operating at a fixed incidence and emission angle (both $45^{\circ}$ ), and the standard used for quantification is a Steel 316 with the following composition: $\mathrm{Cr} 18.45 \%, \mathrm{Mn} 1.63 \%, \mathrm{Fe}$ $65.19 \%$, Ni $12.18 \%, \mathrm{Cu} 0.169 \%$ and Mo $2.38 \%$.

PL measurements were taken with an Olympus microscope (Horiba Jobin Yvon) mounting objectives of $10 \times$, $50 \times$ and $100 \times$ magnifications. The microscope is equipped with a 378-nm laser source with a power of $12 \mathrm{~mW}$ and by a Triax 320 (Horiba Jobin Yvon) spectrometer working in the 200-1500-nm range.
Finally, morphologic information has been obtained by both SEM and AFM microscopies. The SEM images were taken using a Cambridge Stereoscan SEM working with a $20 \mathrm{keV}$ electron beam and a current of $3.4 \mathrm{~mA}$, in secondary electron acquisition mode (SE-SEM) and backscattering acquisition mode (BSE-SEM). The AFM images were taken with a Bruker AFM microscope (Icon Bruker) working in the tapping mode. Each image was taken with a resolution of $512 \times 512$ pixels on an area of a few microns (we took images with a maximum scan size of $5 \times 5 \mu \mathrm{m})$. The AFM images were analyzed by the Nanoscope software by Bruker in order to retrieve the surface roughness and control the damage on the surface on a hundreds of nanometers scale.

After characterization, the samples $\mathrm{C} 1$ and $\mathrm{C} 8$ were subjected to a pulsed laser ablation (PLA) process in order to evaluate its effectiveness in removing the surface patina and to check a possible change in the chemical composition or in morphology. The pulsed laser ablation procedure was performed irradiating for $30 \mathrm{~min}$ each sample with a $\mathrm{Nd}$ :YAG laser of energy $550 \mathrm{~mJ} /$ pulse operating at $1064 \mathrm{~nm}, 20 \mathrm{~Hz}$, with a pulse length of $7 \mathrm{~ns}$ (commercial Quanta-Giant series 710 laser). PLA process was performed in air and in water placing vertically the sample in a 

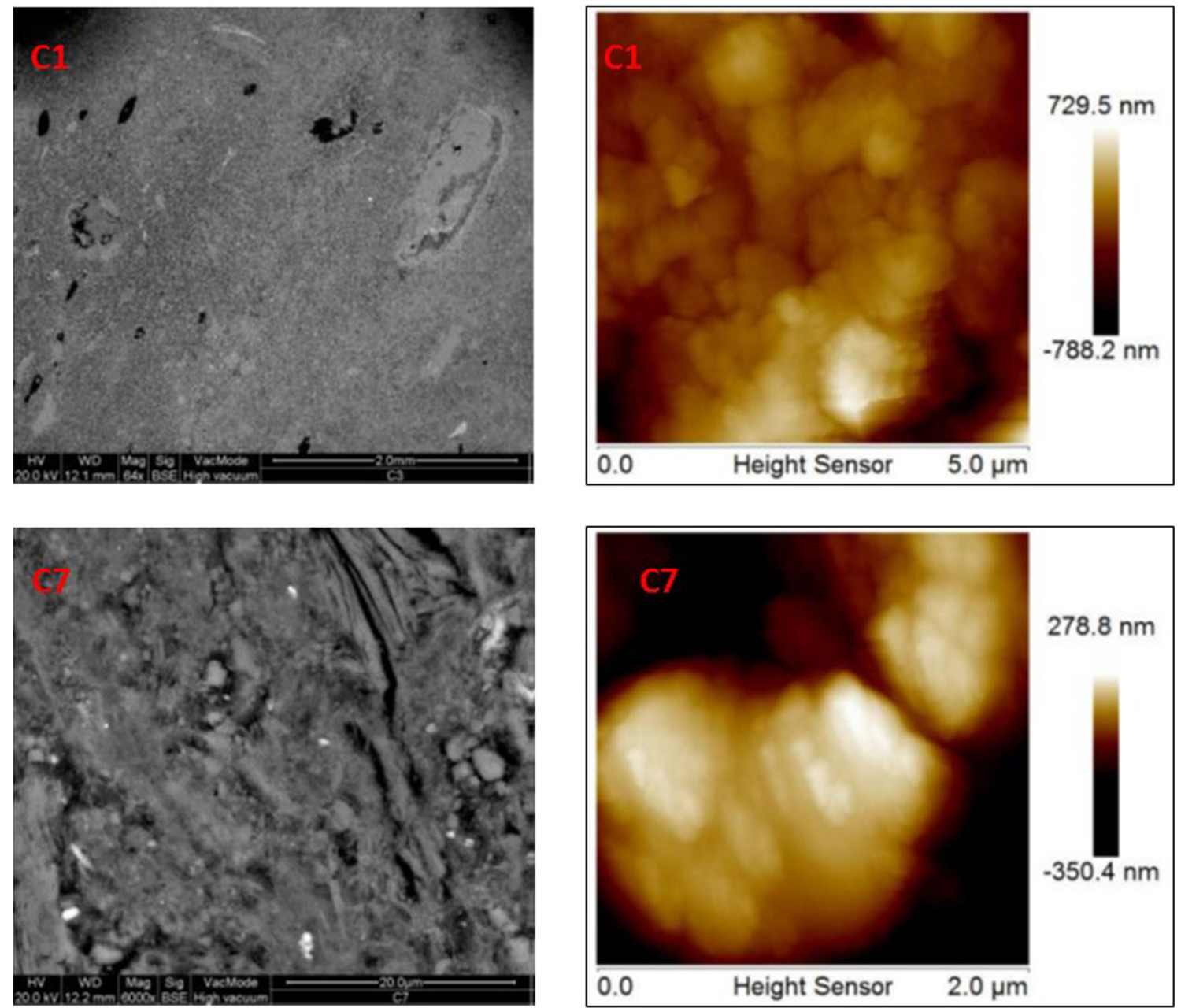

Fig. 2 SEM and AFM images of $\mathrm{C} 1$ and $\mathrm{C} 7$ samples as example for all samples

glass vessel (transparent to the wavelength $1064 \mathrm{~nm}$ ) filled with marine water. The aim of testing PLA in underwater condition is to verify its effectiveness in removing the patina surface in locations with a high level of humidity (such as can be found in Sotterra) or underwater (among the common restoration methods, only the laser ablation can be performed in underwater condition). Finally, the laser ablation cleaning process was compared to the technique of micro-sandblasting [15] conventionally used for the restoration of the external walls of buildings [18]. The blasting drying was performed with a micro-sandblasting on which we mounted nozzles with a diameter from a few tens of microns up to $0.8 \mathrm{~mm}$ and with a working pressure of 2-4 bar.

\section{Results and discussion}

Morphological images of the sample surfaces (see Fig. 2 showing SEM and AFM images of samples $\mathrm{C} 1$ and $\mathrm{C} 7$ as example for all samples) indicate that all samples show the same morphology, consisting in a random distribution of the grains with a size in the order of a few nanometers. Analysis of the surface roughness indicates that the conservation status of each artifact is strongly dependent on the extraction zone, and in fact, a reduced roughness is observed on sample $\mathrm{C} 7$ which comes from the altar (Table 1), but, due to its intrinsic location within the Church, is also the less exposed to usury. As we describe in the following, all the diagnostic methods are in perfect agreement with the AFM analysis and the roughness measurements, indicating that the items extracted from the floor show the same morphological composition and a conservation status perfectly described by the roughness analysis. Moreover, as indicated in the experimental section, the AFM analysis requires fragments with dimensions of the order of few microns, while for petrographic and mineralogical analysis, we need thin sections with dimensions of the order of several millimeters.

The chemical composition information of the samples has been obtained using XRF and XPS spectra (see Fig. 3a, b). The spectra indicate that the main elements on the 
surface are $\mathrm{C}, \mathrm{Si}, \mathrm{O}$ and $\mathrm{Ca}$, with trace elements of $\mathrm{F}, \mathrm{Na}$, $\mathrm{Mg}, \mathrm{Al}, \mathrm{Cl}, \mathrm{K}, \mathrm{Cr}$ and $\mathrm{Fe}$. The main positions of the XPS peaks for each element, summarized in Table 2, are those of pure elements, without formation of chemical bonds between impurities and the matrix. The only exception is represented by the position of a $\mathrm{Ca} 2 \mathrm{p}$ line, at about $351 \mathrm{eV}$, indicating the presence of $\mathrm{Ca}-\mathrm{O}$ or $\mathrm{Ca}=\mathrm{O}$ structures [19] and, then, of a matrix of calcium carbonates $\left(\mathrm{CaCO}_{3}\right)$ [19].

Table 1 Sample roughness evaluated from AFM images

\begin{tabular}{lc}
\hline Sample & Roughness $(\mathrm{nm})$ \\
\hline $\mathrm{C} 1$ & 89 \\
C2 & 166 \\
C3 & 61 \\
C4 & 129 \\
C5 & 52 \\
C6 & 87 \\
C7 & 16 \\
C8 & 96 \\
\hline
\end{tabular}
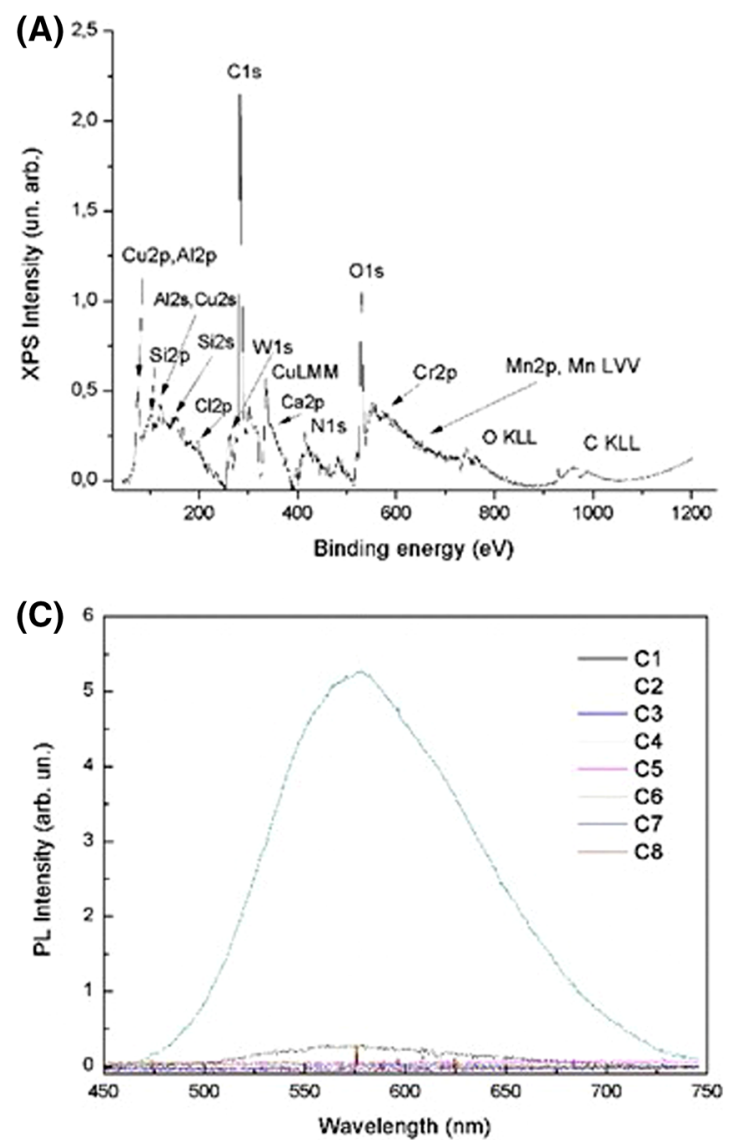

These conclusions are confirmed by a petrographic and mineralogical analysis conducted using optical microscopy $(\mathrm{OM})$ on thin sections. The optical images (in Fig. 4, we show the images for samples $\mathrm{C} 1$ and $\mathrm{C} 7$ as benchmark for all samples) indicate that all the samples are composed in general of a matrix of marl with silico-clastic fragments of granite origin. The different matrixes, as easily obtained from the roughness analysis by AFM images, show a different status of conservation, clearly visible in the grain size of the granite, which varies from gross to fine. In detail, the fragments with higher roughness $(\mathrm{C} 1, \mathrm{C} 2$ and C4) appear, also at petrographic analysis, as the most deteriorated, showing an altered matrix with secondary porosity, while C3, C7 and C8 (lower roughness) show a matrix well preserved without sign of band dissolution.

The found items can therefore be classified as natural stones mainly composed of sedimentary rocks of carbonate in a marl matrix; the different distribution of the aggregate may indicate that the fragments were picked up from different stratigraphic levels of rocks.

Finally, PL measurements in Fig. 3c show a lower intensity of the PL signal, with the exception of C4,
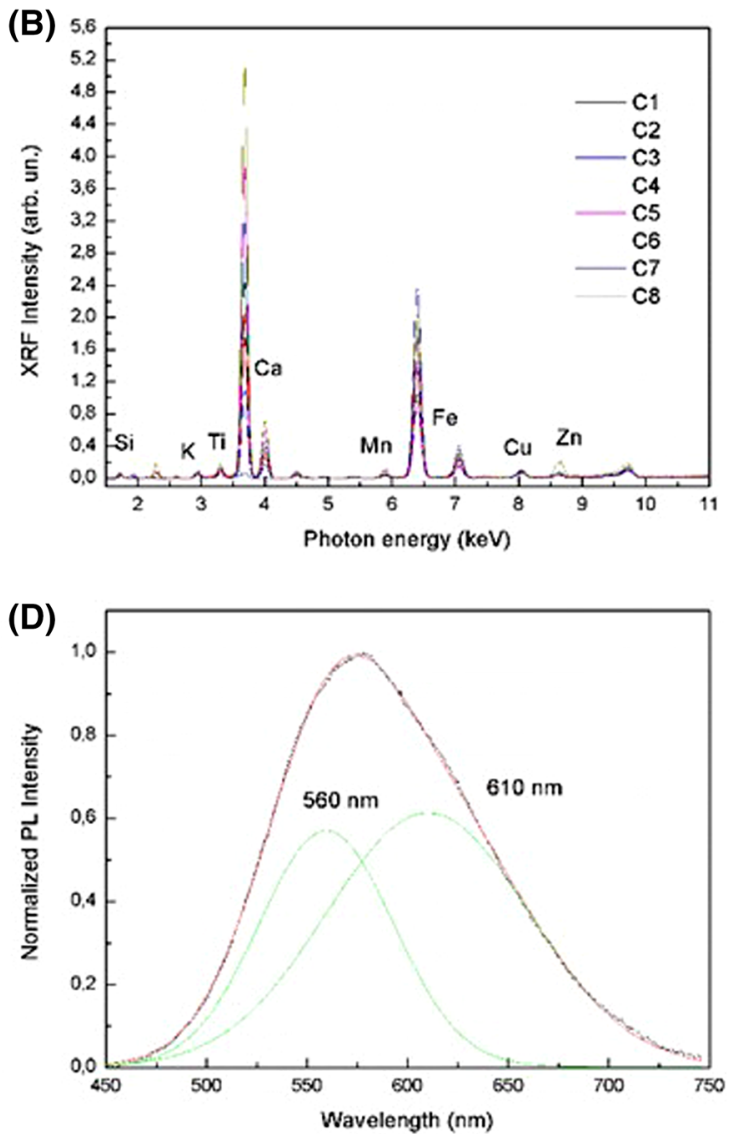

Fig. 3 Chemical analysis on samples: a XPS survey spectrum, XRF (b), photoluminescence (c) and Gaussian analysis of PL spectrum of C4 sample (d) 
Table 2 Positions of main XPS peaks for each element

\begin{tabular}{lllllllll}
\hline & C1 & C2 & C3 & C4 & C5 & C6 & C7 & C8 \\
\hline Si 2p & 103.6 & 103.2 & 103.8 & 102.7 & 102.9 & 102.5 & 103.1 & 103.9 \\
C 1s & 284.2 & 284.8 & 283.4 & 284.1 & 284.8 & 284.2 & 283.8 & 283.9 \\
O 1s & 531.6 & 531.9 & 530.8 & 531.1 & 531.7 & 531.0 & 530.7 & 531.8 \\
Ca 2p & 350.9 & 349.1 & & 351.5 & 350.1 & 349.2 & 351.3 & 348.2 \\
\hline
\end{tabular}

Fig. 4 Optical microscopy images for petrographic analysis (samples $\mathrm{C} 1$ and $\mathrm{C} 7$ as example for all samples)
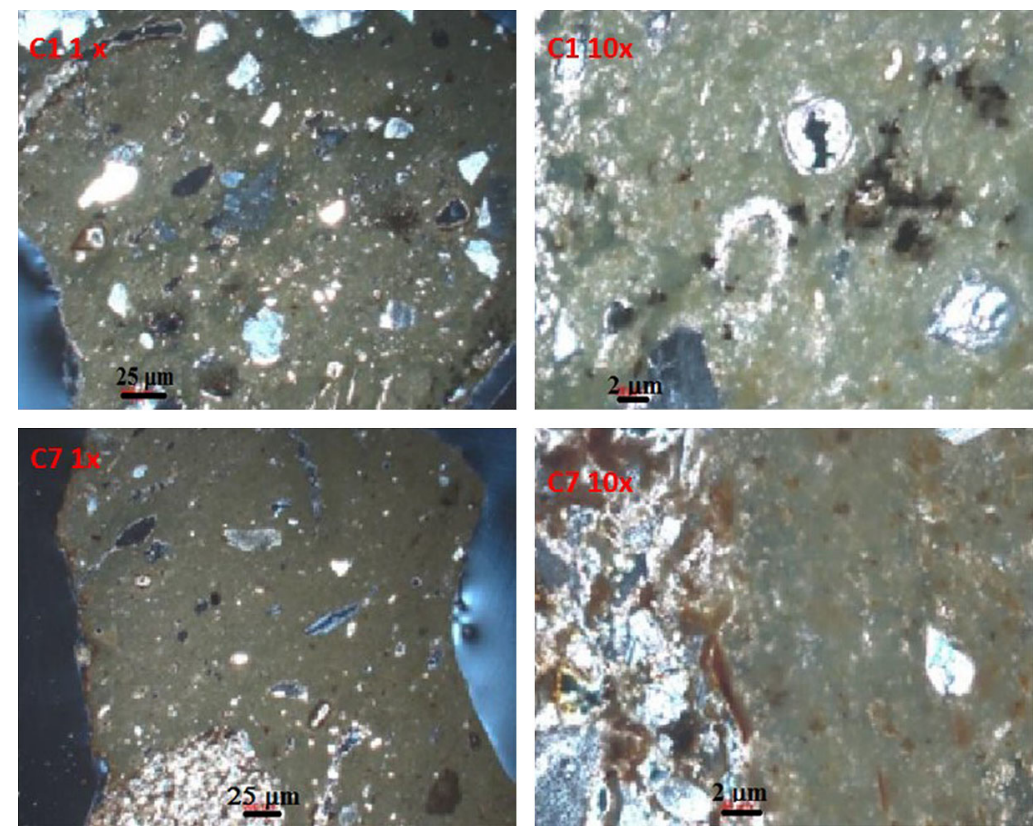

suggesting that the origin and the composition of these fragments are different from those of the others. After a Gaussian analysis (Fig. 3d), the luminescence signal reveals two main bands at 560 and $610 \mathrm{~nm}$, which can be attributed to quartz inclusions $\left(\mathrm{SiO}_{2}\right.$ [20]). In particular, both the bands at 560 and $610 \mathrm{~nm}$ are typical for quartz and are intrinsic of the bulk structure [20].

The comparison between the chemical and mineralogical composition of our findings and a series of previous geological studies on the pits of Calabria [21-24] allows to conclude that the materials used in the Church construction were taken from a quarry found along the Tyrrhenian coast of Northern Calabria, rich in this natural stone [21] and located close to the Church.

As described in the experimental section, pulsed laser ablation cleaning was performed in air (C8) and marine water (C1) to investigate the effectiveness of process for in situ restoration for both terrestrial and underwater sites [17, 25]. In the following, we demonstrate that PLA is much more efficient than classical restoration methods, without causing damages to the artifacts. In the classical laser ablation, the continuous irradiation with a high energetic laser beam can strongly increase the surface temperature (the irradiated area can reach temperatures in the order of a few $1000 \mathrm{~K}$ ) [26]. In
PLA, however, the temperature increases only during the pulse interaction (with a duration in the order of nanoseconds), and the average temperature on the sample surface is in the order of a few hundred $\mathrm{K}$, without damaging the artifacts (Fig. 5a shows the temperature on the irradiated area measured by a J-thermocouple meter placed in the center of the laser spot size). Moreover, with PLA, it is possible to remove only the surface patina, controlling the thickness of the removed layer simply varying the duration of the ablation and without changing the chemical composition of the artifact matrix. The white patina with a thickness of about $500 \mathrm{~nm}$ (mainly composed of carbonates and biological films) located on the stone artifacts has been completely removed after $30 \mathrm{~s}$ of irradiation in marine water and $40 \mathrm{~s}$ in air (SEM images in Fig. 5a, b indicate a zoom of the surface with biological film, before and after the PLA process). The variation of the percentage of constitutive elements, obtained by XPS measurements before and after the PLA (Fig. 5c), demonstrates that PLA, as LA, in water is more effective than in air. In fact, the percentage of $\mathrm{C}$ on the surface increases in the sample ablated in air, indicating absorption of $\mathrm{CO}_{2}$ from the atmosphere. Conversely, the sample ablated in water shows an increase in the percentage of $\mathrm{Si}$ and $\mathrm{Ca}$ and a decrease in $\mathrm{C}$ and $\mathrm{O}$. Cleaning process by micro-sandblasting dry was performed 

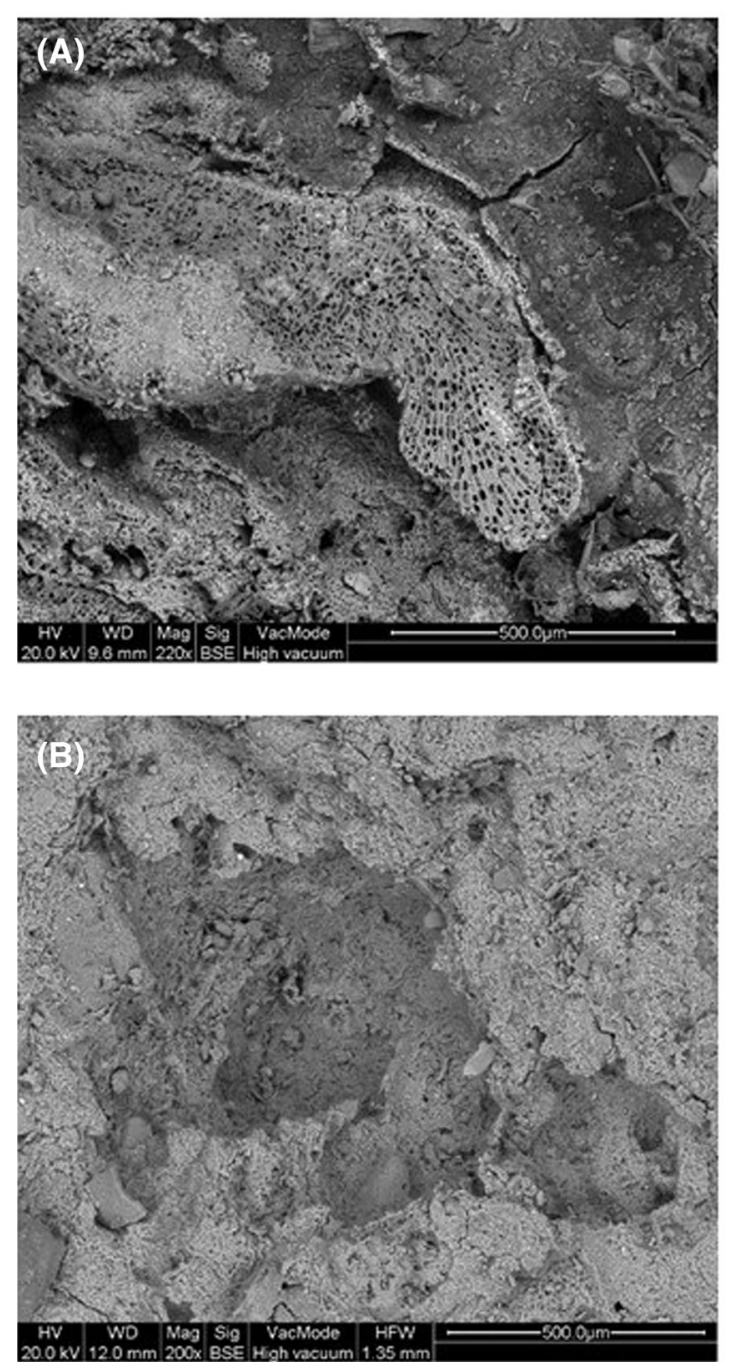

(C)
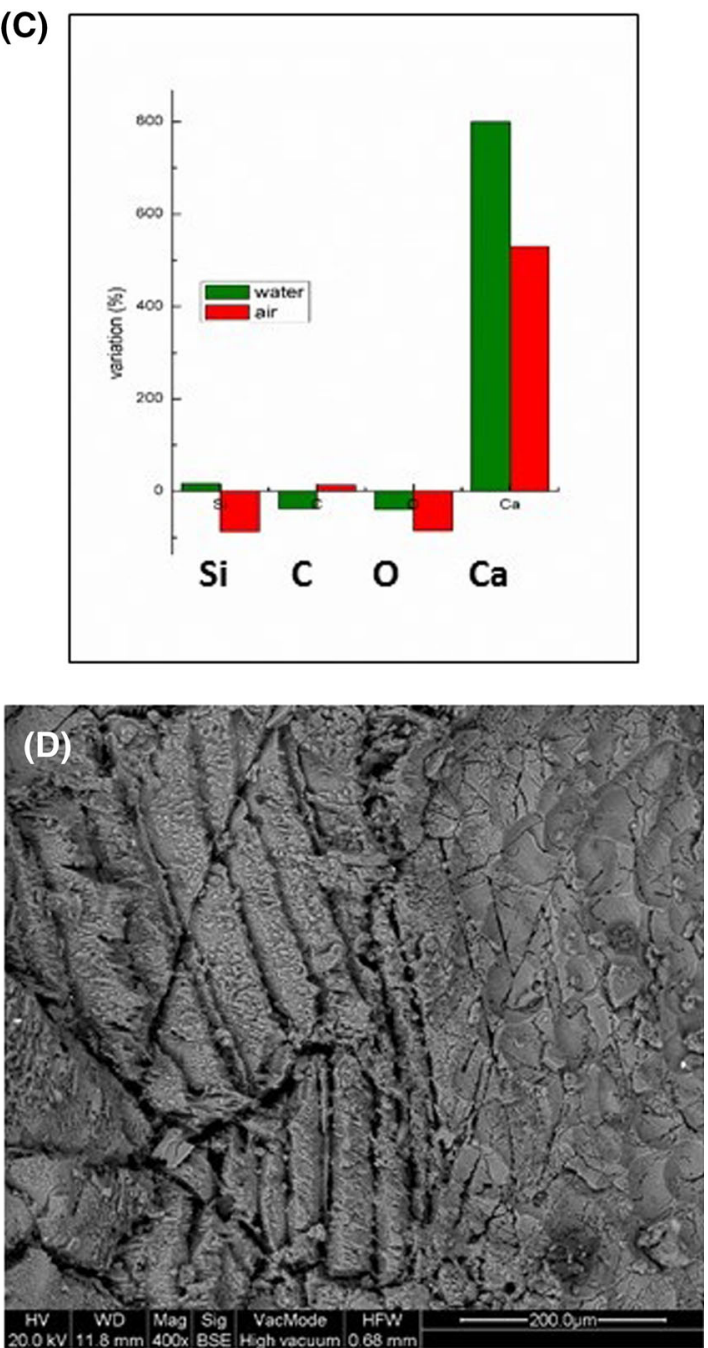

Fig. 5 Variation of surface morphology and chemistry with PLA cleaning on surface; a-b SEM images of biological patina before and after PLA; $\mathbf{c}$ variation of chemical elements on surface verified by XPS analysis before and after PLA; d SEM images after sandblasting cleaning

on sample C6 using grains with dimension of a few hundreds of microns injected at a pressure of 3 bar for a duration of $10 \mathrm{~s}$. As it is well known, this method completely removes the surface patina, but creates on the surface some micro-fractures, which can seriously damage the artifact (see the cracks and fractures created by micro-sandblasting in the SEM images in Fig. 5d). In conclusion, with PLA, it is possible to remove only the surface patina coatings without altering the chemical composition of the samples or creating microfractures, which damage the artworks.

\section{Conclusions}

In this work, we demonstrate that with AFM microscopy, it is possible to control the conservation status of an artwork at nanometric scale, obtaining results which are comparable to classical petrographic and optical methods on micrometric scale. Moreover, we demonstrate the effectiveness of PLA on the controlled removal of a corrosive patina with thickness in the hundreds of nanometers without chemical or morphological damage to the artwork surface.

We compare the two proposed novel methods to classical diagnostics and restoration processes for Cultural Heritage in a case study with findings coming from the Church of Sotterra. The chemical analysis proves that the materials extracted from the Church are the mixture of clay minerals and calcite called "marl" (typical of northwest coast of Calabria); this conclusion is confirmed by petrographic analysis that classifies the samples as carbonate sedimentary rocks.

Acknowledgments The authors thank the Rector of Sotterra Church for the access to Church and the possibility to take the samples for analysis. This work is financially supported by the European Project PON 042a_ Comas, FRQNT/FRQSC (Grant No. 
174726), CRSNG decouverte (Grant No. 435416), NSERC (Grant No. 435416) and ComputeCanada (Job: pve-323-ac, P. Antici). MB is supported by Regional Operative Program (ROP) Calabria ESF 2007/2013-IV Axis Human Capital-Operative Objective M2, ARUE-Project CMN.

\section{References}

1. G. Bitossi, R. Giorgi, M. Mauro, B. Salvador, L. Dei, Appl. Spectrosc. Rev. 40, 187-228 (2005)

2. M.F. La Russa, A. Macchia, S.A. Ruffolo, F. De Leo, M. Barberio, P. Barone, G.M. Crisci, Int. Biodeterior. Biodegrad. 96, 87 (2014)

3. A.D. Carbó, J Solid State Electrochem 14, 349-351 (2005)

4. M. Schreiner, M. Melcher, K. Uhlir, Anal. Bioanal. Chem. 387, 737-747 (2007)

5. C. Urzì, M.C. Valles, M. Vendrell, M. Pernice, Geomicrobiol. J. 16(1), 39-54 (1999)

6. A. De los Ríos, C. Ascaso, Int. Microbiol. 8, 181-188 (2005)

7. L.K. Herreraa, C. Arroyavea, P. Guiametb, S.G. De Saraviab, H. Videlab, Int. Biodeterior. Biodegrad. 54, 135-141 (2004)

8. Th Warscheida, J. Braamsb, Int. Biodeterior. Biodegrad. 46, 343-368 (2000)

9. L.K. Herrera, H.A. Videla, Int. Biodeterior. Biodegrad. 54, 125-134 (2004)

10. A.J. López, T. Rivas, J. Lamas, A. Ramil, A. Yáñez, J. Mater. Sci. Process. 100, 733-739 (2010)

11. F. Russo, Origini e sviluppo della città di Paola,. Tip. La Nuovissima: Acerra (1971)
12. A.M. Panno, La chiesa ipogea di Sotterra (sec. IX-X) (Cosenza, Editoriale Progetto, 2007)

13. G. Chidichimo, F. Dalena, in Proceedings of the V International Conference on the Rock Civilization, (2011)

14. P. Pouli, M. Oujja, M. Castillejo, J. Mater. Sci. Process. 106, 447-464 (2012)

15. D. Camuffo, Microclimate for Cultural Heritage: Conservation, Restoration and Maintenance of Indoor and Outdoor Monuments, 2nd edn. (Elsevier, San Diego, 2014)

16. UniNormal Regulations: http://www.icr.arti.beniculturali.it/Nor mal/Normal.htm

17. M. Barberio, P. Barone, F. Stranges, D. Renzelli, F. Xu, A. Bonanno, J. Phys. Sci. Appl. 4, 224-228 (2013)

18. S. Rescic, P. Tiano, F. Fratini, R. Manganelli del Fa, Eur. J. Environ. Civ. Eng. 17(2), 113-127 (2013)

19. XPS data base: http://srdata.nist.gov/xps/

20. PL data base: http://www.csiro.au/luminescence/

21. E. DiSipio, A. Galgaro, E. Destro, G. Teza, S. Chiesa, A. Giaretta, A. Manzella, J. Environ. Earth Sci. 72, 1383-1401 (2014)

22. G. De Filippis, M. Giudici, G. Margiotti, F. Mazzone, S. Negri, C. Vassena, Ital J. Groundw. AS04016, 17-28 (2013). doi:10. 7343/AS-016-013-0040

23. G. De Filippis, S. Margiotta, S. Negri, M. Giudici, Environ. Earth Sci. 67, 1891-1907 (2012). doi:10.1007/s12665-012-1631-1

24. M. Giudici, S. Margiotta, F. Mazzone, S. Negri, C. Vassena, Environ. Earth Sci. (2012). doi:10.1007/s12665-012-1631-1

25. B. Davidde, J. Naut. Archaeol. 31(21), 83-88 (2002)

26. S.I. Anisimov, B.S. Luk'yanchuk, Phys. Usp. 45(3), 293-324 (2002) 